\title{
Two New Ceruloplasmin Variants in Negroes-Data on Three Populations
}

\author{
M. H. K. Shokeir ${ }^{1,2}$ and D. C. Shreffler ${ }^{1}$ \\ Received 7 Jan. 1970-Final 9 March 1970
}

Two new electrophoretic variants in human serum ceruloplasmin are described. The first, called $\mathrm{Cp}$ New Haven $(\mathrm{CpNH})$, is determined by an allele at the same autosomal locus which controls the previously described $C p A$ and $C p B$ variants. It migrates with $a$ mobility between $C p B$ and $C p C$. The variant has been encountered in American as well as Nigerian and Haitian Negroes. The minimal estimate of $\mathrm{Cp}^{\mathrm{NH}}$ gene frequency in American Negroes is about 0.006. The second variant, named Cp Bridgeport (Cp Bpt), has a mobility between $C p A$ and $C p B$. It apparently has an extremely low frequency. Similar to $\mathrm{CpNH}$, the $\mathrm{Cp}$ Bpt genetic determinant seems to be an autosomal codominant gene. Its relationship to $\mathrm{Cp}^{\mathrm{A}}, \mathrm{Cp}^{\mathrm{C}}$, and $\mathrm{Cp} \mathrm{p}^{\mathrm{NH}}$ is, however, unknown. The frequencies of $C p$ variants in a number of populations are presented.

\section{INTRODUCTION}

Ceruloplasmin, a copper-containing serum $\alpha-2$ globulin, was described in 1948 by Laurell and Holmberg. The copper, which confers intense blue coloration on the protein, constitutes the prosthetic group in the enzymatic oxidase activity displayed by ceruloplasmin, particularly toward aromatic diamines. The nature of ceruloplasmin function, however, is not clearly understood. Recent work suggests its possible involvement in the enzymatic transfer of copper to copper-containing enzymes (Shokeir and Shreffler, 1969a).

In 1967, Shreffler et al. reported electrophoretic variation in serum ceruloplasmin from American Negroes. The electrophoretic variants detected were a common form, $\mathrm{CpB}$, a faster form, $\mathrm{CpA}$, and a slower one, $\mathrm{CpC}$. The $\mathrm{CpA}$ and $\mathrm{CpB}$ forms were shown to be controlled by a pair of codominant autosomal alleles. The relationship of the hereditary determinant of $\mathrm{CpC}$ to these alleles was not clearly elucidated.

\footnotetext{
This work was supported in part by USAEC contract AT (11-1) 1552 and by USPHS Career Development Award 6-K 3 HE-24, 980 (to D.C.S.).

1 University of Michigan, Ann Arbor, Michigan.

2 Present address: Section of Medical Genetics, Department of Pediatrics, University of Saskatchewan, Saskatoon, Saskatchewan, Canada.
} 
Further work on sera from American Negroes has disclosed two new variants. The first migrates on starch gel electrophoresis midway between the $\mathrm{CpB}$ and $\mathrm{CpC}$ types. The other occupies an intermediate position between the $\mathrm{CpB}$ and $\mathrm{CpA}$ forms under the same conditions. In conformity with the suggestion put forward by Shreffler et al. (1967), these two new variants have been named $\mathrm{Cp}$ New Haven (CpNH) and $\mathrm{Cp}$ Bridgeport $(\mathrm{Cp} \mathrm{Bpt})$, respectively, after the locations of the families in which they were first recognized.

\section{MATERIALS AND METHODS}

\section{Sera and Plasmas}

\section{Negroes}

American Negroes. Sera or ACD (acid-citrate-dextrose) plasmas were obtained from Negro individuals from New Haven, Bridgeport, Waterbury, and Hartford, Connecticut; Detroit and Jackson, Michigan; Charleston and James Island, South Carolina; Savannah and Claxton, Georgia; and New York City, N.Y. Sera were separated from clotted blood specimens drawn in plain vacuum tubes and plasmas were separated from blood to which ACD was added as an anticoagulant. A total of 2278 samples were typed. Of these, 1126 were random individuals (including 848 parents in family units) and 1152 were offspring in families.

Northern Nigerian Negroes. Sera were obtained from 520 individuals of the Tiv, Izzi, and Idoma ethnic divisions in Benue Province and from Idala, Basakomo, and Igalla in Kabba Province. The following villages were surveyed: Mbayem, Gagoiboward, Mbatser, Akuba, Agadagba, Enugba, Egede, Mbayion, Ngambe, and Mbashintiev.

Haitian Negroes. Serum samples were collected from 323 individuals from Haiti. The sample was mostly from a rural, peasant population. Virtually no Indian (Leyburn, 1941) and only slight Spanish and French admixtures (Rodman, 1954) have contributed to the composition of the sampled population. Specifically, our sample was derived from the villages of Cayemites, Anse a Macon, and Pointe Sable, whose populations were 2569,853, and 475, respectively, as of March 1968.

\section{Caucasians}

A total of 1270 samples obtained from American Caucasians were surveyed. Most of these came from the town of Tecumseh, Michigan, and were made available through the Tecumseh Community Health Study, Department of Epidemiology, School of Public Health, University of Michigan (Francis, 1961).

\section{Amerindians}

A total of 720 samples were typed. These included 594 Yanomama (Waica) and 126 Makiritare Indians from Venezuela (Arends et al., 1967).

\section{Starch Gel Electrophoresis}

Horizontal starch gel electrophoresis was used in all cases. The method is substantially 
as described by Smithies (1955). Connaught hydrolyzed starch (Connaught Medical Research Laboratories, Toronto, Canada, Lot 245-1); 11.8 g per $100 \mathrm{ml}$ borate gel buffer ( $0.16 \mathrm{M}$ boric acid and $0.010 \mathrm{M}$ sodium hydroxide, $p \mathrm{H} 9.55)$, was employed. With electrostarch (Electrostarch Co., Madison, Wisconsin, Lots No. 174 and 350), $11.8 \mathrm{~g}$ of starch per $100 \mathrm{ml}$ borate gel buffer $(0.12 \mathrm{M}$ boric acid and $0.0074 \mathrm{M}$ sodium hydroxide, $p \mathrm{H}$ 9.55) was used. The cell buffer with either type of starch was $0.21 \mathrm{M}$ boric acid and $0.085 \mathrm{M}$ sodium hydroxide, $p \mathrm{H}$ 9.0. Electrophoresis was carried out at $4 \mathrm{C}$ for $21 \mathrm{hr}$ at $8 \mathrm{v} / \mathrm{cm}$. Serum samples were routinely diluted one third before electrophoresis to diminish the intensity of ceruloplasmin staining, enhance the resolution, and provide better distinction of the variants.

\section{Immunoelectrophoresis}

Immunoelectrophoresis was performed on 8 by $10 \mathrm{~cm}$ glass slides with No. 2 Ionagar (Consolidated Laboratories, Chicago Heights, Illinois) as the supporting medium. The buffer system and electrophoretic conditions were those described by Hirschfeld (1959).

\section{Staining}

Ceruloplasmin was detected and localized after starch gel electrophoresis by a slight modification of the method of Owen and Smith (1961). Gels were sliced horizontally in half, and the bottom layer was stained by incubation in a solution of $0.1 \% \mathrm{o}$-dianisidine and $30 \%$ ethanol in $0.03 \mathrm{~m}$ sodium acetate buffer, $p \mathrm{H} 5.5$, for $1-1 \frac{1}{2} \mathrm{hr}$ at $37 \mathrm{C}$. At this stage, ceruloplasmin bands were well defined when the gels were examined on an $\mathrm{X}$-ray illuminator. Both phenotypic classification and photography were performed at this time, since storage usually led to a broadening and diffusion of the bands which rendered subsequent classification quite difficult.

Staining of the precipitin bands on immunoelectrophoresis plates was achieved by the use of amido black followed by destaining in methanol-acetic acid solution (10 vol methanol: 10 vol distilled water: 4 vol glacial acetic acid).

\section{RESULTS}

\section{New Haven Variant}

The variants previously encountered in human serum ceruloplasmin are shown in Fig. 1. The new $\mathrm{CpNH}$ variant has been found to occur in association with both $\mathrm{CpA}$ and $\mathrm{CpB}$ forms in the $\mathrm{CpA} \mathrm{NH}$ and $\mathrm{CpB} \mathrm{NH}$ phenotypes, respectively. The $\mathrm{CpNH}$ variant, when compared with the slow variant described previously, $\mathrm{CpC}$, is found to occupy a position intermediate between the common $\mathrm{CpB}$ and the rare $\mathrm{CpC}$ forms (Fig. 2).

The $\mathrm{S}$ family (Fig. 3), from New Haven, Connecticut, in which the variant was first detected, represents a $\mathrm{CpAB} \times \mathrm{CpA} \mathrm{NH}$ mating. From this mating, four phenotypes were produced, $\mathrm{CpA}, \mathrm{CpAB}, \mathrm{CpB} \mathrm{NH}$ and $\mathrm{CpA}$ NH. This outcome is consistent with allelism between the genetic determinant of $\mathrm{CpNH}$ and the $C p^{A}$ and $C p^{B}$ alleles. The recovery of $\mathrm{CpB} \mathrm{NH}$ and $\mathrm{CpA}$, as well as the two parental phenotypes $\mathrm{CpAB}$ and 


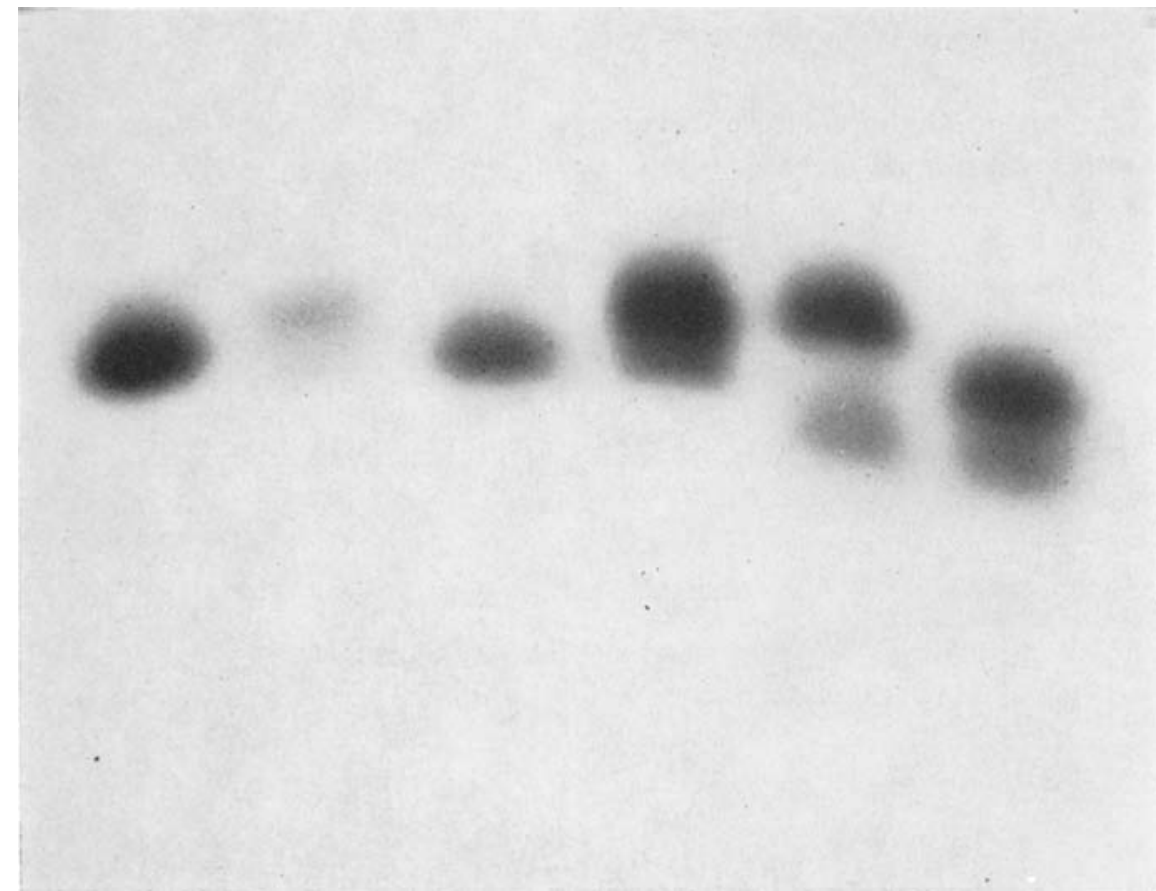

Fig. 1. Ceruloplasmin patterns of (from left to right) $\mathrm{CpB}, \mathrm{CpAB}, \mathrm{CpB}, \mathrm{CpAB}, \mathrm{CpAC}$, and $\mathrm{CpBC}$ sera after electrophoresis on starch gel and staining with $a$-dianisidine. The anode is at the top.

Fig. 2. Ceruloplasmin patterns of (from left to right) $\mathrm{CpBC}, \mathrm{CpB} N H, C p A B, C p B N H$, $\mathrm{CpA} \mathrm{NH}$, and CpAC sera after electrophoresis on starch gel and staining with $o$-dianisidine. The anode is at the top. 


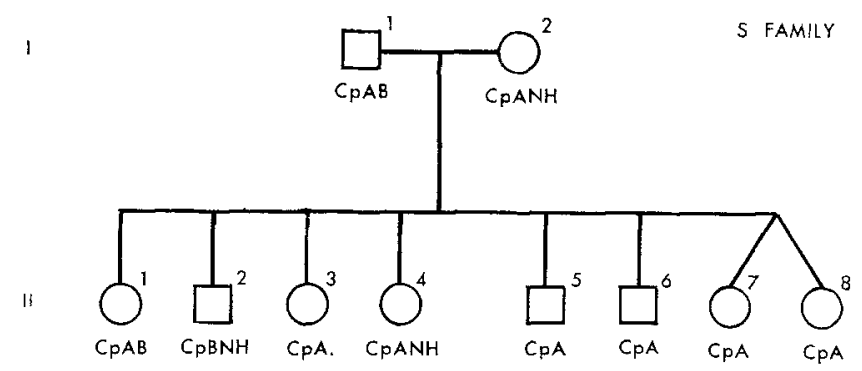

Fig. 3. Pedigree $\mathrm{S}$ showing segregation of $\mathrm{CpNH}$ variant.

$\mathrm{CpA} \mathrm{NH}$, supports the hypothesis that $\mathrm{CpA}$ and $\mathrm{CpB}$ and $\mathrm{CpNH}$ are determined by three alleles at a single autosomal locus. The surplus of $\mathrm{CpA}$ offspring (4 CpA : 1 $\mathrm{CpAB}: 1 \mathrm{CpB} \mathrm{NH}: 2 \mathrm{CpA} \mathrm{NH}$ ) in this family can be attributed to chance.

The W family, from Charleston, South Carolina (Fig. 4), involved the same mating types, $\mathrm{CpAB} \times \mathrm{CpA} \mathrm{NH}$. The two offspring ascertained are both $\mathrm{CpB} \mathrm{NH}$-the critical type for demonstration of allelism between $C p^{N H}, C p^{A}$, and $C p^{B}$.

\section{Bridgeport Variant}

Figure 5 shows a starch gel electrophoresis result of a $\mathrm{Cp} B$ pt $\mathrm{B}$ serum. As demonstrated in the figure, $\mathrm{Cp} \mathrm{Bpt}$ migrates with a mobility faster than that of $\mathrm{CpB}$. The $\mathrm{Cp} \mathrm{Bpt} \mathrm{band} \mathrm{is} \mathrm{further} \mathrm{characterized} \mathrm{by} \mathrm{its} \mathrm{marked} \mathrm{intensity} \mathrm{when} \mathrm{compared} \mathrm{to} \mathrm{the}$ $\mathrm{CpB}$ band, which together with their close mobility renders clear resolution of the two bands rather difficult. The electrophoretic typing was, however, confirmed by the use of a variety of other techniques such as immunoelectrophoresis, determination of the total serum ceruloplasmin oxidase activity, and response of this activity to inhibitors

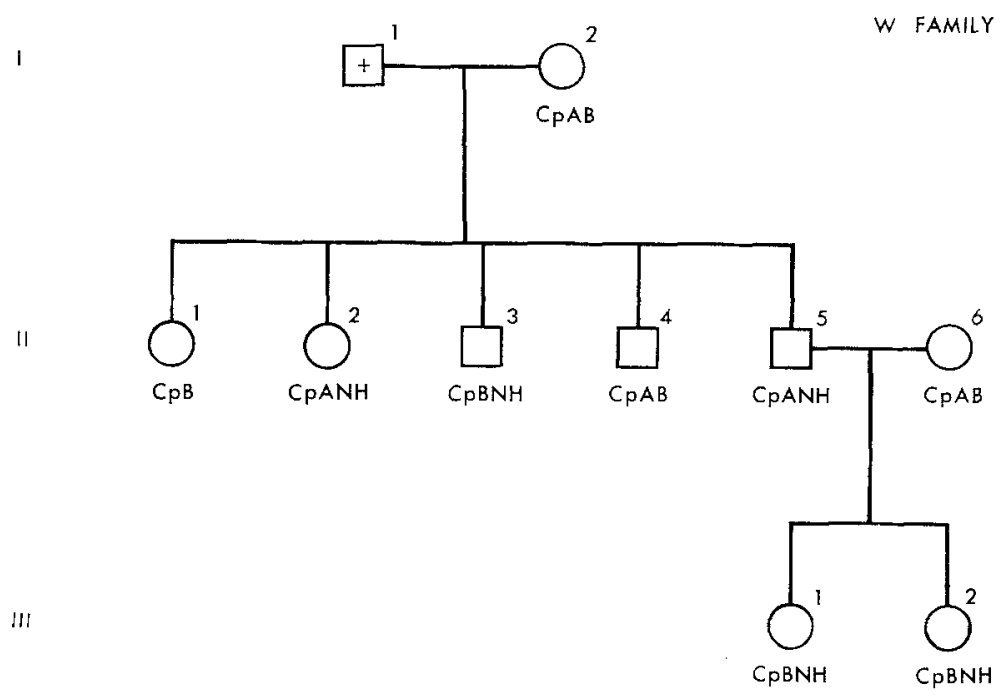

Fig. 4. Pedigree W showing segregation of $\mathrm{CpNH}$ variant. 


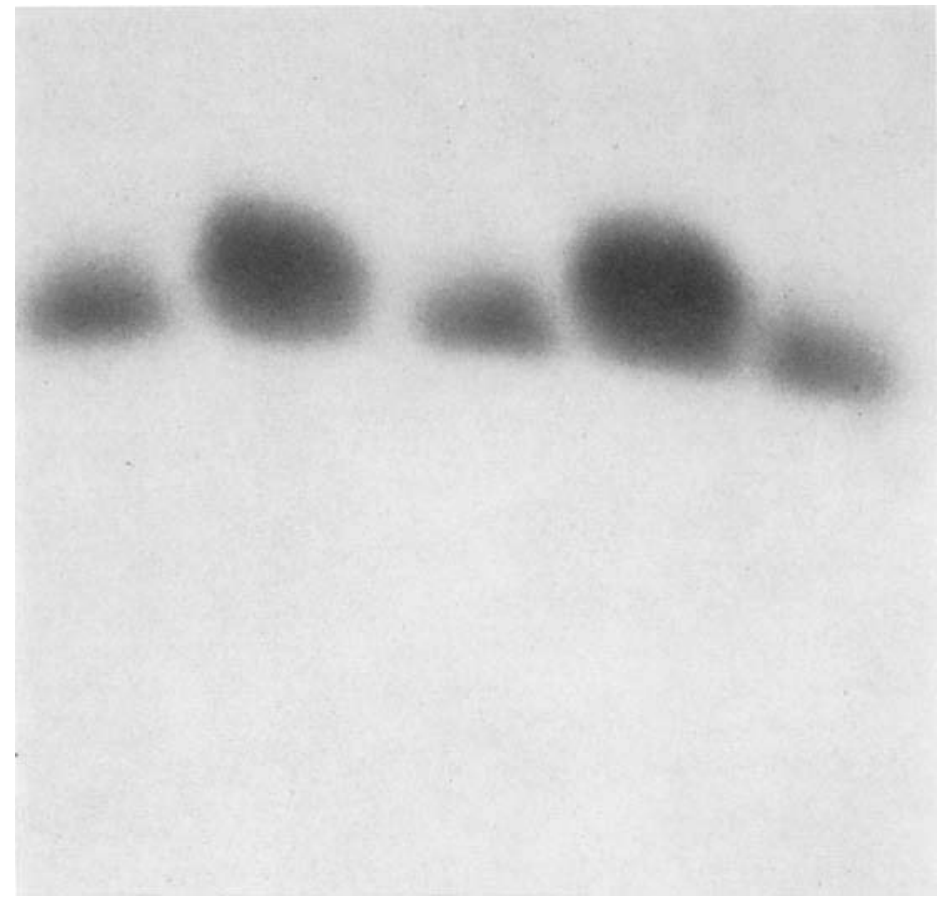

Fig. 5. Ceruloplasmin patterns of (from left to right) $\mathrm{CpB}, \mathrm{Cp} B \mathrm{Bt} \mathrm{B}, \mathrm{CpB}$, $\mathrm{Cp} \mathrm{Bpt} \mathrm{B}$, and $\mathrm{CpB}$ sera after electrophoresis on starch gel and staining with $o$-dianisidine. The anode is at the top.

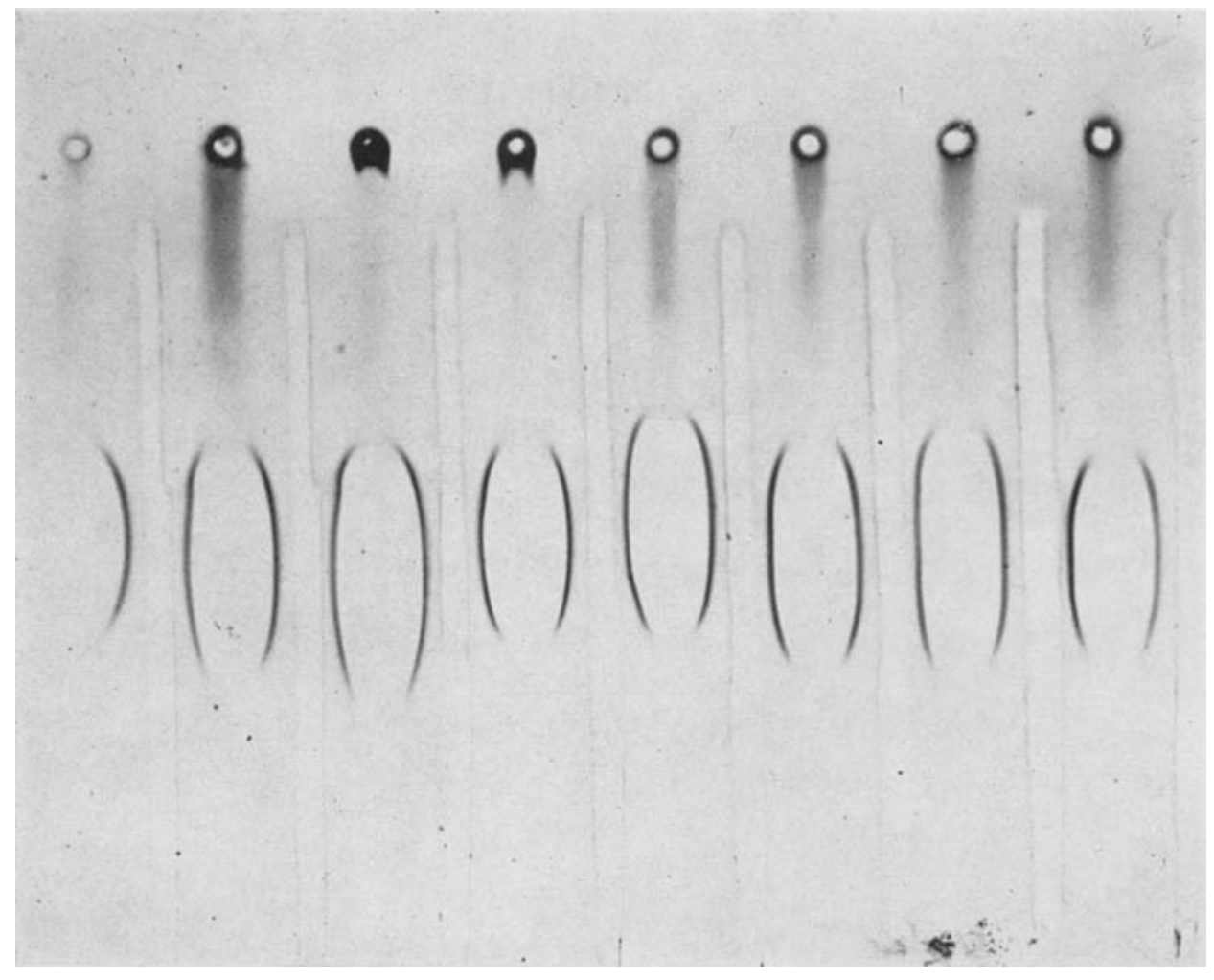

Fig. 6. Immunoelectrophoretic patterns of eight ceruloplasmin phenotypes (from left to right) $\mathrm{CpB}$ : Cp Bpt B, CpAB, CpB NH, CpBC, CpA NH, CpAC, CpB NH. The anode is at the bottom. 


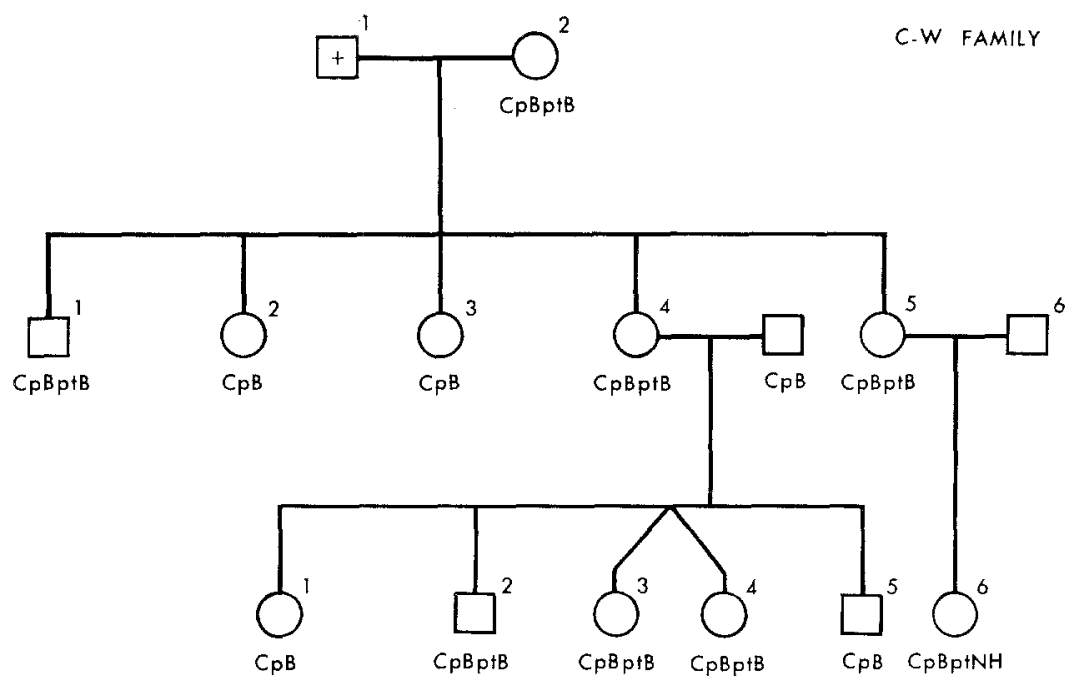

Fig. 7. Pedigree $\mathrm{C}-\mathrm{W}$ showing segregation of $\mathrm{Cp} B$ pt variant.

(Shokeir and Shreffler, 1969b). On immunoelectrophoresis (Fig. 6), the position of the $\mathrm{Cp}$ Bpt precipitin band was midway between that of the $\mathrm{CpB}$ form and $\mathrm{CpA}$ form, just as on starch gel.

In Fig. 7 is presented an extensive pedigree which shows segregation of the $\mathrm{Cp}$ Bpt variant. The pattern of transmission of the trait suggests codominant autosomal inheritance.

Table I summarizes all of the matings encountered in the American Negro sample, their frequency, the observed numbers of offspring resulting from these matings, and the expected numbers assuming allelism of the hereditary determinants of the $\mathrm{CpA}$, $\mathrm{CpB}, \mathrm{CpNH}$, and $\mathrm{CpC}$ variants. The remarkable agreement between observed and expected values supports the hypothesis of four codominant alleles. Furthermore, note that the $\mathrm{CpAC} \times \mathrm{CpB}$ mating gave rise to offspring of $\mathrm{CpAB}$ and $\mathrm{CpBC}$ phenotypes, thereby providing an evidence for allelism of the $\mathrm{CpC}$ determinant to $C p^{A}$ and $C p^{B}$ alleles. Three exceptions are noted in the table; two of these are children with the $\mathrm{CpAB}$ phenotype, allegedly the offspring of parents both of whom are of the $\mathrm{CpB}$ phenotype. In both, alleged paternity was confidently excluded by disparity in the inheritance of the $\mathrm{ABO}$ system. The third was a child of the $\mathrm{CpB}$ phenotype, whose mother was $\mathrm{CpB}$ and whose putative father was $\mathrm{CpA}$. That child's paternity, however, could not be reliably excluded.

\section{Population Studies \\ American Negroes}

A total of 2278 sera were obtained from American Negroes for purposes of electrophoretic classification of ceruloplasmin types. Of these, 1126 were considered to constitute a genetically random sample which included unrelated individuals and the 


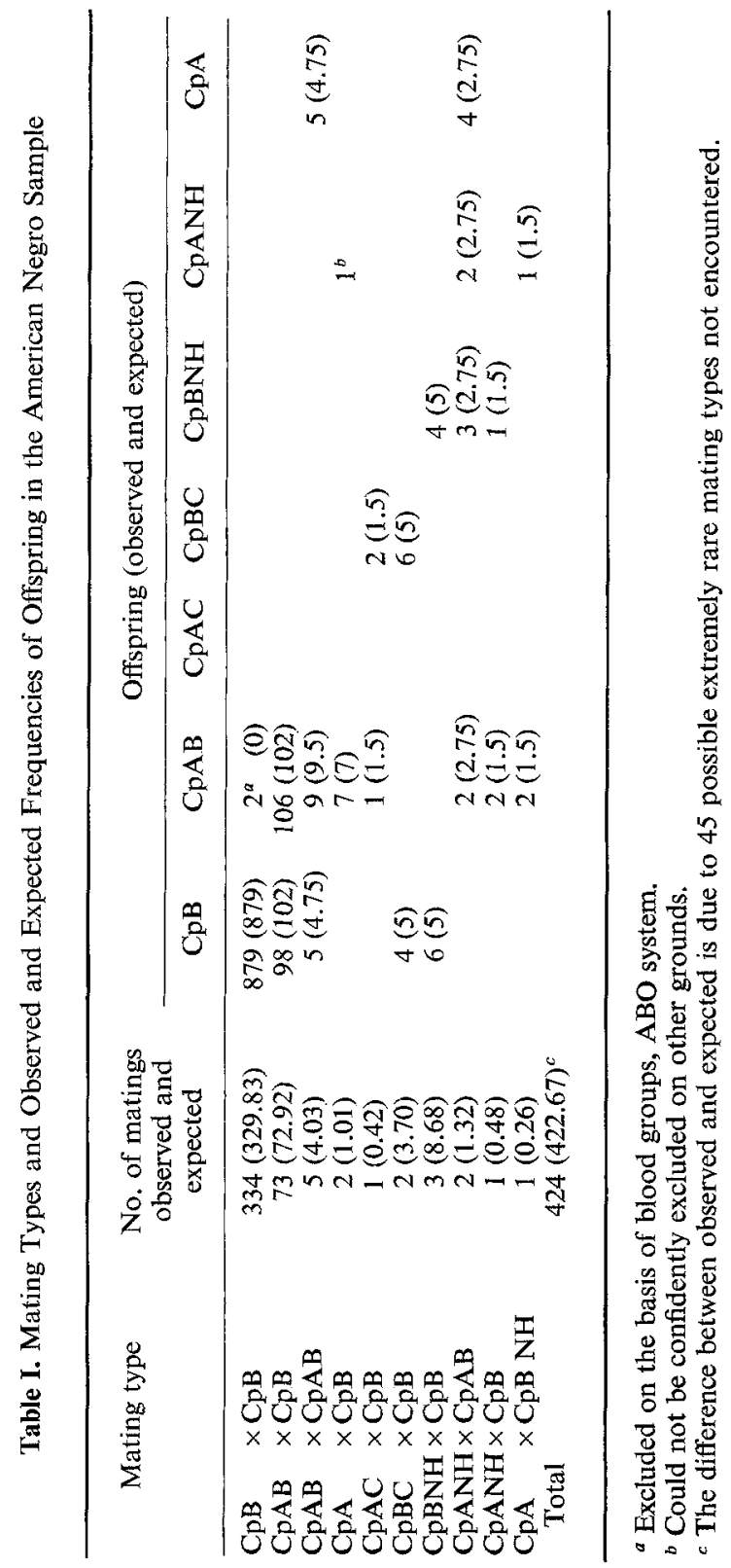


Table II. Phenotype and Allele Frequencies Among Independently Ascertained American Negroes

\begin{tabular}{lrr|ll}
\hline Phenotype & Observed & Expected & Allele & Frequency \\
\hline $\mathrm{CpB}$ & 997 & 993.2 & $C p^{B}$ & 0.9392 \\
$\mathrm{CpAB}$ & 106 & 109.77 & $C p^{A}$ & 0.0519 \\
$\mathrm{CpA}$ & 3 & 3.02 & $C p^{N H}$ & 0.0062 \\
$\mathrm{CpB} \mathrm{NH}$ & 10 & 13.11 & $C p^{C}$ & 0.0027 \\
$\mathrm{CpA} \mathrm{NH}$ & 4 & 0.73 & & \\
CpBC & 5 & 5.71 & & \\
CpAC & 1 & 0.32 & & \\
Total & 1126 & 1125.98 & Total & 1.0000 \\
& & & & \\
\hline
\end{tabular}

parents in the various matings investigated. The offspring of these matings were not included, since their genotypes were determined by those of their parents. The numbers in different phenotypic classes together with the computed expectations according to Hardy-Weinberg distribution are listed in Table II. There is a good fit between observation and expectation, except in the case of $\mathrm{CpA}$ NH phenotype, which occurs in excess.

Gene frequencies for this sample of American Negroes, computed from the observed phenotype frequencies under the assumption of allelism, are listed in Table II. They are in accord with those previously reported for the $C p^{A}, C p^{B}$, and $C p^{C}$ alleles $(0.053,0.944$, and 0.003, respectively, Shreffler et al., 1967).

The estimate for the $C p^{N H}$ allele is, in all probability, an underestimate, because of the difficulty in the early part of the survey in resolution and recognition of the $\mathrm{CpB}$ NH phenotype. This difficulty is manifested in Table II in the excess of CpA NH and deficiency of $\mathrm{CpB} \mathrm{NH}$ phenotypes, relative to expectation.

\section{Nigerian Negroes}

In order to obtain an estimate of the frequency of the Cp variants in African Negroes, 520 serum samples from individuals living in Northern Nigeria were obtained and typed.

Table III. Phenotype and Allele Frequencies Among Negroes from Northern Nigeria

\begin{tabular}{lrr|ll}
\hline Phenotype & Observed & Expected & Allele & Frequency \\
\hline CpB & 364 & 363.89 & $C p^{B}$ & 0.8365 \\
CpAB & 129 & 129.62 & $C p^{A}$ & 0.1490 \\
CpA & 12 & 11.55 & $C p^{N H}$ & 0.0115 \\
CpB NH & 10 & 10.04 & $C p^{C}$ & 0.0029 \\
CpA NH & 2 & 1.79 & & \\
CpBC & 3 & 2.51 & & \\
CpAC & 0 & 0.45 & & \\
$\quad$ Total & 520 & 519.35 & Total & 0.9999 \\
& & & & \\
\hline
\end{tabular}


Table IV. Phenotype and Ailele Frequencies Among Negroes from Haiti

\begin{tabular}{lcc|ll}
\hline Phenotype & Observed & Expected & Allele & Frequency \\
\hline CpB & 246 & 246.45 & $C p^{B}$ & 0.8735 \\
CpAB & 64 & 63.8 & $C p^{A}$ & 0.1131 \\
CpA & 4 & 4.13 & $C p^{N H}$ & 0.0119 \\
CpB NH & 6 & 6.7 & $C p^{C}$ & 0.0015 \\
CpA NH & 2 & 0.87 & & \\
CpBC & 1 & 0.84 & & \\
CpAC & 0 & 0.10 & & \\
Total & 323 & 322.89 & Total & 1.0000 \\
\hline
\end{tabular}

The observed and expected phenotypic frequencies are shown in Table III. Again, the fit is very good. All four of the variant types found more than once in the random. American Negro sample were also found in this sample, including the two rare variants $\mathrm{CpC}$ and $\mathrm{CpNH}$. The gene frequencies calculated from these data are presented in Table III. The frequency of $C p^{A}$ is approximately 0.15 , almost three times that in the American Negro.

\section{Haitian Negroes}

Samples of sera from 323 Haitian Negroes were classified. The observed and expected distributions of phenotypic classes are shown in Table IV. Again the four variant ceruloplasmin types found in the American and African samples were also found here. The gene frequencies calculated from this sample are summarized in Table IV. The $C p^{A}$ allele in this sample displays an intermediate frequency $(0.11)$ between that in the Nigerian American Negroes.

\section{Caucasian}

Among the 1270 Caucasian samples examined, three independent instances of ceruloplasmin electrophoretic variation were observed. Electrophoretically, and by inhibition studies (Shokeir and Shreffler, 1969a), they were indistinguishable from the CpA of the Negro. They may represent rare occurrences of the Negro gene in the Caucasian population. In three families in which segregation of the variant was observed codominant autosomal inheritance was indicated. The responsible allele occurs with a frequency of 0.0025 in the sample surveyed.

\section{Amerindians}

As a representative of the American Indian population, the sample studied from the Yanomama and Makiritare Indians is patently restricted. Of 720 sera typed, only one independent occurrence of an electrophoretic variant segregating in a single family was detected, a fast-migrating type in combination with $\mathrm{CpB}$.

In view of the obvious limitation of the sample investigated, no categorical statement can be made about the occurrence and frequency of ceruloplasmin electrophoretic variation in the American Indian population. 


\section{DISCUSSION}

The two ceruloplasmin variants described above are detectable by both starch gel electrophoresis and immunoelectrophoresis. $\mathrm{CpNH}$ has been consistently found in various samples of the American Negro population independently obtained from individuals dispersed over six states. It has been further encountered in both Nigerian and Haitian Negroes. Family studies show that it is transmitted as a simple autosomal trait, and is determined by a codominant allele at the same autosomal locus which controls the $\mathrm{CpA}$ and $\mathrm{CpB}$ variants.

The observed frequency of the CpA NH phenotype in the American Negro sample exceeds the expectation according to the Hardy-Weinberg distribution, whereas that of the CpB NH phenotype falls below the expected level (Table II). The most plausible interpretation of this incongruity is a failure to detect the $\mathrm{CpB} N H$ phenotype in the earlier part of the study. It is likely that the CpB NH phenotype was frequently misclassified as $\mathrm{CpB}$. It appears, however, that refinement in the technique and cognizance of the $\mathrm{CpB} \mathrm{NH}$ phenotype enabled more consistent recognition of this phenotype in the latter part of the study. This is shown in the studies on sera from Northern Nigerian and Haitian Negroes, where this difficulty has been averted and a better fit between observation and expectation obtained. This observation demonstrates that genetic polymorphism may go unnoticed or grossly underestimated. The frequency of the $C p^{N H}$ allele in American Negroes may be substantially higher than 0.006 . Indeed, the frequency displayed by this variant in the Haitian and Nigerian studies approaches the polymorphic level.

The occurrence of the serum ceruloplasmin variants $\mathrm{CpA}, \mathrm{CpC}$, and $\mathrm{CpNH}$ in three divergent Negro populations-of presumably common origin-which have been separated for the last 10-12 generations attests to the antiquity of the mutations which produced them. Their appearance must have preceded the separation of the New World Negroes from their African ancestors, that is, before the termination of slave importation to the Western Hemisphere.

The persistence of these variants, especially of $\mathrm{CpA}$, which occurs in polymorphic frequency, suggests the possibility that they may confer some selective advantage. Further support is provided by comparing the frequency of $C p^{A}$ allele in American Negroes, about 0.05 , with that in Nigerians, where it reaches 0.15 . Such a decline in frequency cannot be accounted for simply by admixture, since the Caucasian contribution to the gene pool of the American Negro has been variably estimated to be between 0.2 (Workman et al., 1963) and 0.3 (Stern, 1953; Glass and Li, 1953), the former being more recent and reliable. When used to derive estimates of Caucasian admixture in the American Negroes, disparity in the frequency of ceruloplasmin variation between American and West African Negroes yields a figure as high as 0.66 -reminiscent of that based upon the frequency of sickle cell hemoglobin. As in the case of the latter, the decline in the frequency of the allele $C p^{A}$ can be most readily ascribed to selective differences in the African and American environments.

The nature of the presumed selective advantage conferred upon individuals possessing variant ceruloplasmin forms in the African environment is, as yet, purely speculative. It might possibly relate to differences in the efficiency with which various 
ceruloplasmin forms function in the enzymatic transfer of copper to the vital coppercontaining enzymes such as cytochrome oxidase (Shokeir and Shreffler, 1969a). For example, a reduced efficiency of copper transfer by $\mathrm{CpA}$, in the heterozygous combination $\mathrm{BpAB}$, could critically jeopardize the survival of parasites such as Plasmodium falciparum with minimal or no adverse effect on the host. Homozygotes of the CpA type, however, might have diminished fitness. Such a mechanism may account for the frequency of the $\mathrm{CpA}$ variant in Africa, where malaria is both endemic and prevalent.

In contrast to the widely distributed $\mathrm{CpNH}$, the new $\mathrm{Cp} B$ pt variant has been definitively encountered only once, in a single family in which the variant segregates in a fashion consistent with autosomal codominance with the common $\mathrm{CpB}$ form. The relationship of $\mathrm{Cp} B \mathrm{Bpt}$ to the $\mathrm{CpA}, \mathrm{CpC}$, and $\mathrm{CpNH}$ forms is not known, although in individual III 6 (Fig. 7) the phenotype is $\mathrm{Cp}$ Bpt NH, where the two newly discovered variants apparently occurred in a heterozygous combination. This suggests, but does not prove, allelism with $C p^{N H}$.

\section{ACKNOWLEDGMENTS}

The authors wish to acknowledge the help of Drs. J. V. Neel, J. C. Gall, Jr., and G. J. Brewer of the University of Michigan, L. R. Weitkamp of the University of Rochester, and Wilbur Downs of Yale University in generously providing serum samples for typing and classification.

\section{REFERENCES}

Arends, T., Brewer, G., Chagnon, N., Callango, M. L., Gershowitz, H., Layrisse, M., Neel, J., Shreffler, D., Tashian, R., and Weitkamp, L. (1967). Intratribal genetic differentiation among the Yanomama Indians of southern Venezuela. Proc. Natl. Acad. Sci. 57: 1252.

Francis, T., Jr. (1961). Aspects of the Tecumseh study. Public Health Rep. 76: 963.

Glass, B., and Li, C. C. (1953). The dynamics of racial intermixture: An analysis based on American Negroes. Am. J. Human Genet. 5: 1.

Hirschfeld, J. (1959). Immunoelectrophoretic demonstration of qualitative differences in human sera and their relation to haptoglobin. Acta Pathol. Microbiol. Scand. 47: 160.

Holmberg, C. G., and Laurell, C. B. (1948). Investigation in serum copper: II. Isolation of copper containing protein and a description of some of its properties. Acta Chem. Scand. $5: 476$.

Leyburn, J. G. (1941). The Haitian People, Yale University Press, New Haven, Conn.

Owen, J. A., and Smith, H. (1961). Detection of ceruloplasmin after zone electrophoresis. Clin. Chim. Acta 6: 441 .

Rodman, S. (1954). Haiti: The Black Republic, The Denvir-Adair Co., New York.

Shokeir, M. H. K., and Shreffler, D. C. (1969a). Cytochrome oxidase deficiency in Wilson's disease: A suggested ceruloplasmin function. Proc. Natl. Acad. Sci. 62: 867.

Shokeir, M. H. K., and Shreffler, D. C. $(1969 b)$. Characterization of ceruloplasmin variants: A proposed model for control of quantitative expression. Am. Soc. Human Genet. Abst. $10: 12$.

Shreffler, D. C., Brewer, G. J., Gall, J. C., and Honeyman, M. S. (1967). Electrophoretic variation in human serum ceruloplasmin: A new genetic polymorphism. Biochem. Genet. 2: 101.

Smithies, O. (1955). Zone electrophoresis in starch gels: Group variations in the serum proteins of normal human adults. Biochem. J. 61: 629.

Stern, C. (1953). Modal estimates of the frequency of white and near white segregants in the American Negro. Acta Genet. 4: 281.

Workman, P. L., Blumberg, B. S., and Cooper, A. J. (1963). Selection, gene migration and polymorphic stability in a U.S. white and Negro population. Am. J. Human Genet. 15: 429. 